\title{
Urticaria crónica espontánea: revisión de la literatura
}

\author{
Spontaneous chronic urticaria: \\ A literature review
}

\author{
Liliana M. Guevara-Saldaña MD', \\ July Ospina-Cantillo MD', \\ Ricardo Cardona-Villa MSc ${ }^{2}$
}

Resumen: la urticaria crónica espontánea es una enfermedad que produce gran compromiso en la calidad de vida del paciente y de la que aún se desconocen, en gran parte, los mecanismos fisiopatológicos asociados, ya que no son generalizables en todos los individuos. Existen factores intrínsecos y extrínsecos implicados en el desarrollo y persistencia de la enfermedad, los cuales pueden actuar de forma individual o coexistente. En esta revisión se proponen algunos cambios en la clasificación actual de la enfermedad, donde se incluye una subdivisión dentro de la urticaria crónica denominada urticaria crónica mixta, la cual hace referencia a los casos donde coexisten factores intrínsecos y extrínsecos para la aparición de la enfermedad en el mismo individuo. Algunos procesos infecciosos virales, bacterianos y parasitarios se han asociado en el desarrollo o severidad de los síntomas de la urticaria crónica en un subgrupo de pacientes, por lo tanto, son incluidos como factores extrínsecos del individuo dentro de las urticarias crónicas inducibles no físicas. Estas modificaciones son propuestas con el fin de optimizar el diagnóstico y manejo de los pacientes con urticaria crónica mixta.

Palabras clave: urticaria, urticaria crónica espontánea, urticaria crónica mixta, infecciones parasitarias, Helicobacter pylori.

Guevara-Saldaña LM, Ospina-Cantillo J, Cardona-Villa R. Urticaria crónica espontánea: revisión de la literatura. Medicina \& Laboratorio 2017; 23: 331-350.

${ }^{1}$ Médicas, Residentes de Alergología Clínica, Grupo de Alergología Clínica y Experimental (GACE), Universidad de Antioquia. Medellín, Colombia.

${ }_{2}^{2}$ Médico, especialista en Alergología Clínica, MSc en Inmunología. Docente titular, Universidad de Antioquia. Investigador senior, Director Grupo de Alergología Clínica y Experimental (GACE). Medellín, Colombia. Correspondencia: calle 64 \# 51 - 31, IPS Universitaria, sede Ambulatoria, Servicio de Alergología. Teléfono: 5744937090 ext. 30106.

Correo electrónico: rcv2016udea@gmail.com

Conflicto de intereses: los autores declaran que no tienen conflicto de intereses. Medicina \& Laboratorio 2017; 23: 331-350

Módulo 29 (Dermatología), número 2. Editora Médica Colombiana S. A. 2017.

Recibido el 29 de junio de 2017; aceptado el 25 de agosto de 2017 
a urticaria comprende un grupo heterogéneo de enfermedades que son relativamente comunes en la población general y tienen un gran impacto en la calidad de vida. Esta se caracteriza por la aparición de habones pruriginosos, que pueden estar presentes en cualquier región corporal $y$, en menor frecuencia, angioedema. Las lesiones de la urticaria ocurren debido a la degranulación de los mastocitos, que se activan por mecanismos inmunológicos (mediante activación linfocitaria) y no inmunológicos (por activación directa de los mastocitos), lo cual induce la liberación de mediadores inflamatorios intracelulares preformados y de síntesis de novo [1,2]. Estos mediadores ocasionan los signos y síntomas característicos de la enfermedad como prurito, aumento de la permeabilidad vascular y edema. Característicamente los habones se resuelven en menos de 24 horas de su aparición, mientras que el angioedema se resuelve de forma más tardía, entre las 24 y 72 horas, y no dejan lesión residual en la piel afectada $[1,2]$.

En esta revisión se pretende realizar una amplia descripción de los mecanismos fisiopatológicos de la enfermedad, su diagnóstico, clasificación y manejo.

\section{Clasificación de la urticaria}

La urticaria se puede dividir en aguda y crónica, según la duración de los síntomas. La urticaria aguda se define por la presencia de habones que duran menos de seis semanas y cuya ocurrencia es espontánea o en respuesta a un desencadenante, que típicamente se trata de infecciones virales o reacciones alérgicas a medicamentos, alimentos, látex o insectos $[1,3]$. Por su parte, en la urticaria crónica los habones aparecen intermitentemente durante seis semanas o más; tradicionalmente, se ha subdividido según la presencia o ausencia de factores desencadenantes en urticaria crónica espontánea y urticaria crónica inducible [1-3]. La urticaria crónica espontánea ocurre sin un desencadenante aparente, lo cual indica un proceso intrínseco de la enfermedad, mientras que la urticaria crónica inducible ocurre cuando la formación de habones es reproducible después de un estímulo externo específico. Esta última puede ser una urticaria inducible física, como es el caso del dermografismo sintomático, la urticaria por frío, por presión, por luz solar o por calor y el angioedema vibratorio, o ser una urticaria inducible no física, como la urticaria por contacto, la acuagénica y la colinérgica [4].

En un estudio multicéntrico, prospectivo y descriptivo, realizado en una población tomada de una cohorte previamente formada durante el desarrollo del ensayo clínico URTICA (del inglés, Urticaria Research of Tropical Impact and Control Assessment), proveniente de las ciudades de Medellín y Bogotá (Colombia), se logró demostrar, en un subgrupo de 245 pacientes con urticaria crónica espontánea, que en el $36,3 \%$ de ellos la exposición a uno o más factores externos (por medio de pruebas de provocación) desencadenaban también la aparición de los síntomas característicos, donde el dermografismo sintomático fue la causa más frecuente, seguido de la presión, lo que permitió demostrar la existencia de una posible superposición entre la urticaria crónica espontánea y la urticaria crónica inducible [5]. 

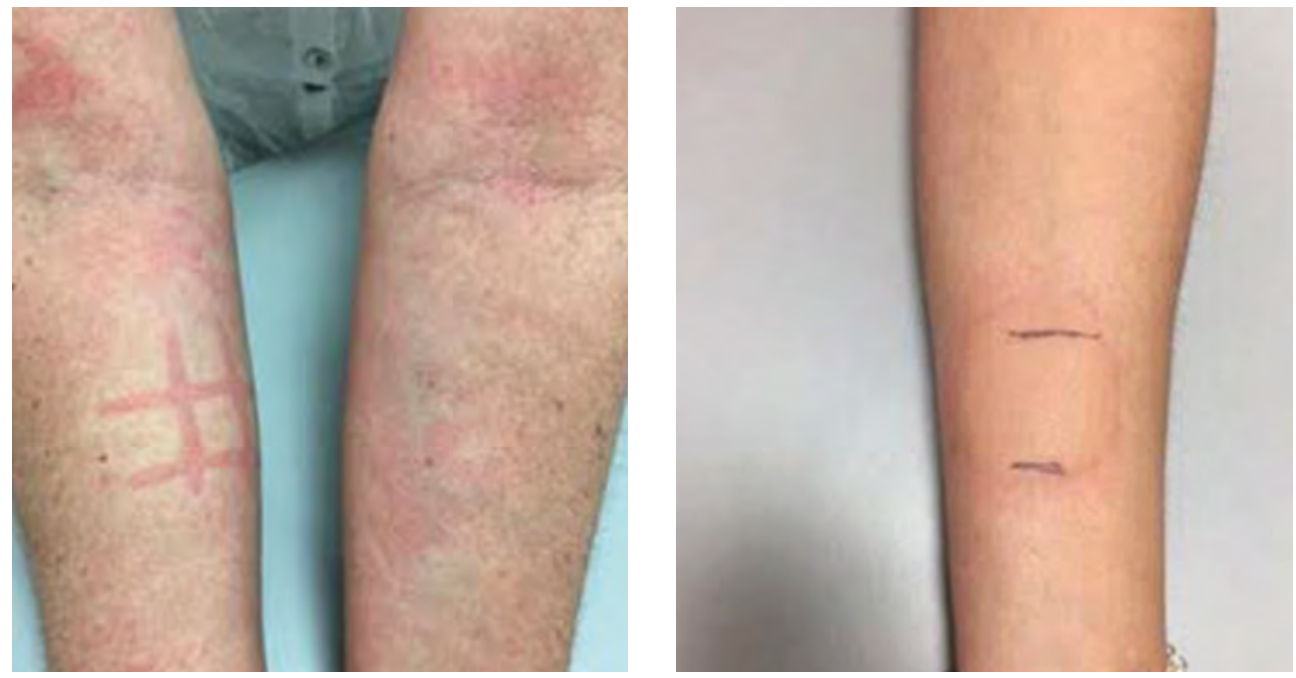

Figura 1. Pruebas de provocación para la demostración de urticaria crónica espontánea con componente inducible (dermografismo y frío). A. Prueba de provocación para dermografismo positiva. Obsérvese la formación de habón y eritema con el roce superficial en el antebrazo derecho. La paciente refería prurito. B. Prueba de provocación con cubo de hielo positiva. Obsérvese la formación de habón y eritema a los 15 minutos después del contacto directo del cubo de hielo en la superficie del antebrazo izquierdo. Cortesía del Servicio de Alergología, IPS Universitaria, sede Ambulatoria. Medellín, Colombia.

Algunas infecciones se han asociado al desarrollo o la exacerbación de los síntomas de la urticaria crónica espontánea, como es el caso de las parasitosis intestinales y las infecciones por Helicobacter pylori, aunque los mecanismos fisiopatológicos aún no son claros. Además, su participación en la urticaria crónica espontánea es cuestionable, ya que no son un factor intrínseco del paciente $y$, como se ha descrito en algunos reportes de casos y metanálisis, se comportan más como un factor desencadenante de la urticaria crónica, que al ser eliminado lleva a la resolución de los síntomas $[6,7]$.

En relación con lo anterior, en nuestra institución se presentó un caso clínico en el que se observó la sobreposición de la urticaria crónica espontánea y la inducible: mujer de 51 años, con cuadro de habones pruriginosos de un año de evolución, con lesiones que aparecían casi a diario en cualquier parte del cuerpo, con una duración de menos de 24 horas y que no dejaban lesiones residuales. Las lesiones estaban asociadas a edema en los párpados y se exacerbaban con el frío; además, la paciente refería la aparición de los habones con el rascado o al frotarse. Se le realizaron pruebas de provocación con cubo de hielo y de fricción con objeto romo, ambas positivas (véase figura 1). Se le indicó tratamiento con fexofenadina a una dosis de $180 \mathrm{mg}$ cada 8 horas por vía oral, para el que presentó adecuada respuesta y buen control de los síntomas.

Teniendo en cuenta lo anterior, se propone incluir en la clasificación de esta condición patológica a la urticaria crónica mixta, en la que se encontraría el subgrupo de 


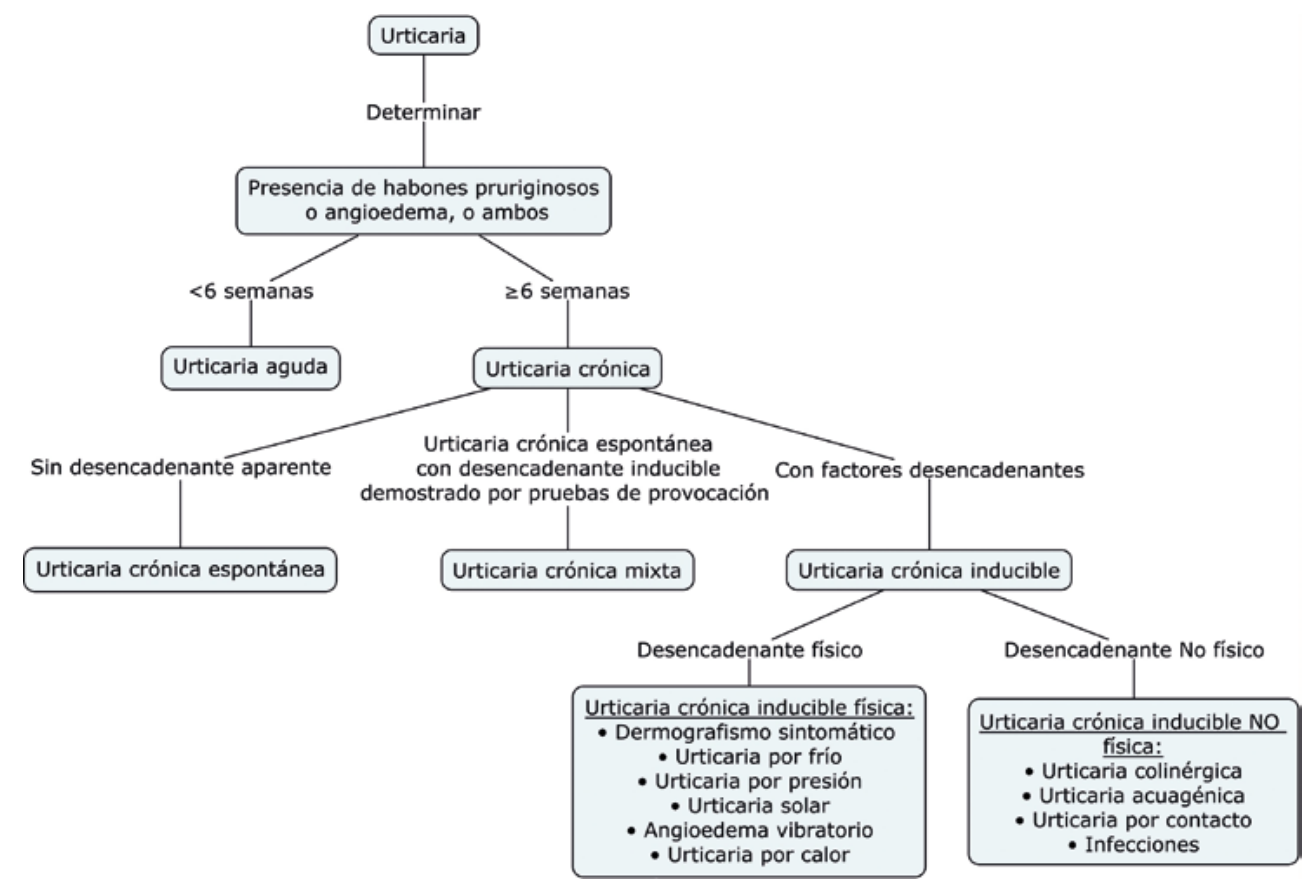

Figura 2. Clasificación propuesta para la urticaria.

pacientes que presentan urticaria crónica espontánea con coexistencia de urticaria crónica inducible; además, incorporar a las infecciones como estímulo no físico de la urticaria crónica inducible (véase figura 2).

\section{Prevalencia de la urticaria}

La urticaria aguda afecta alrededor del 15\% al $30 \%$ de la población general y la urticaria crónica entre el $0,5 \%$ y el $5 \%$. La prevalencia de la urticaria es dos veces más frecuente en las mujeres que en los hombres y aqueja un grupo etario entre los 20 y 40 años de vida, aunque también se han reportado casos en la infancia y la adolescencia $[1,5]$.

La urticaria crónica es una entidad autolimitada con una duración de un año en el $30 \%$ al $50 \%$ de los pacientes; el $90 \%$ de los pacientes presentan remisión de la enfermedad a los cinco años de su inicio y solo en un $5 \%$ los síntomas persisten más allá de este tiempo y es en quienes se ha demostrado una mayor severidad de los mismos y resistencia al tratamiento con antihistamínicos [1,3]. 
Mecanismos fisiopatológicos de la urticaria crónica espontánea

En los habones urticariales se observa edema de la dermis, vasodilatación y un infiltrado perivascular no necrotizante que incluye principalmente linfocitos $\mathrm{T} \mathrm{CD4} 4^{+}$, neutrófilos, eosinófilos, monocitos y basófilos $[3,8]$. La neutrofilia dérmica es evidente a los 60 minutos de evolución del habón. La activación inapropiada de los mastocitos es característica al inicio de la enfermedad y la liberación del contenido celular marca la fase inmediata de la inflamación; posteriormente, ocurre una reacción de hipersensibilidad mediada por linfocitos y granulocitos que se hace evidente como habones. Las células inflamatorias liberan más citoquinas proinflamatorias, con mayor reclutamiento de células, lo que amplifica la respuesta $[3,8]$.

A continuación, se describirán los diferentes mecanismos fisiopatológicos que se han propuesto para explicar la secuencia de eventos que se observan durante la enfermedad; sin embargo, se hipotetiza que varios de estos mecanismos pueden coexistir $[3,8]$.

\section{Autoinmunidad}

El origen autoinmune es la hipótesis más aceptada para explicar la activación y degranulación alterada de los mastocitos en la urticaria. Estos mecanismos se apoyan debido a los siguientes hallazgos e hipótesis.

\section{Alta prevalencia de autoanticuerpos antitiroideos}

Diferentes estudios han mostrado una mayor prevalencia de autoanticuerpos antiperoxidasa tiroidea y antitiroglobulina en los pacientes con urticaria crónica espontánea en comparación con los controles sanos [8-10].

\section{Reacción de habón o exacerbación de la urticaria tras la inyección de suero autólogo intradérmico en pacientes y su reproducibilidad con la transferencia pasiva del suero a sujetos sanos}

La prueba cutánea con suero autólogo (ASST, por sus siglas en inglés) no prueba la presencia de anticuerpos, pero muestra las propiedades de la liberación de la histamina del suero que es probado, lo que explica un mecanismo de autorreactividad más que de autoinmunidad $[3,9]$. La sensibilidad y la especificidad de esta prueba intradérmica para la detección de anticuerpos en pacientes con urticaria crónica espontánea son del $80 \%$ cuando se compara con el ensayo de liberación de la histamina de basófilos in vitro. Sin embargo, en la población sana el ASST puede ser positivo en un $30 \%$ de los casos $[8,10]$.

\section{Identificación de anticuerpos IgG contra el $\alpha$-FceRI de la IgE}

La presencia de autoanticuerpos dirigidos contra la subunidad $\alpha$ del receptor de alta afinidad de la región Fc épsilon (FcERI) de la inmunoglobulina $E$ (IgE) se ha demostrado en el $26 \%$ los pacientes con urticaria crónica espontánea [11]. Estos autoanticuerpos son inmunoglobulinas tipo $\mathrm{G}$ (IgG), subtipos IgG1 e IgG3, con capacidad de liberar histamina y activar el complemento $[1,8,12,13]$; también pueden ser de tipo inmunoglobulina $M(\operatorname{IgM})$, aunque son menos frecuentes $[9,13]$. Por su parte, en el $15 \%$ de los pacientes se pueden encontrar anticuerpos anti-FceRI que son inmunoreactivos, pero que no son funcionales, es decir, que no inducen la liberación de la histamina [11].

Asimismo, se ha evidenciado hasta en el $70 \%$ en los pacientes con urticaria crónica 
espontánea la presencia del autoanticuerpo dirigido contra el receptor de baja afinidad de la IgE, el FceRII/CD23 (receptor presente en la superficie del eosinófilo), el cual induce la degranulación del mastocito por estímulo de la proteína básica mayor (PBM) liberada por el eosinófilo [12-14]. De igual manera, pueden existir autoanticuerpos tipo IgE en el $9 \%$ de los pacientes [11] y otros anticuerpos que aún no han sido identificados $[8,12,13,15]$.

Finalmente, se han encontrado factores liberadores de histamina específicos de mastocitos en el $9 \%$ de los pacientes con urticaria crónica espontánea, y en el $41 \%$ de ellos puede no identificarse factor alguno [11].

\section{Asociación positiva con el HLA subtipos DRB*04 (DR4) y B*14}

Las determinaciones de los alelos del antígeno leucocitario humano (HLA) clase 2 , en pacientes con urticaria crónica espontánea, han mostrado un incremento en la expresión del HLA-DRBI*04, y su alelo asociado, el DQB*0302 (DQ8); además, una fuerte asociación de estos con la actividad liberadora de histamina de los basófilos en suero, la autorreactividad o ambos [16]. Igualmente, se ha encontrado una mayor prevalencia del HLA B*14 en los pacientes con urticaria crónica espontánea positivos para la antiperoxidasa tiroidea con una razón de momios de 10,43 [17]. Estos hallazgos son consistentes con la base autoinmune de la enfermedad.

\section{Respuesta terapéutica a la plasmaféresis y la inmunoglobulina intravenosa}

Una evidencia indirecta a favor del mecanismo autoinmune en los pacientes con urticaria crónica espontánea es la respuesta de estos pacientes al tratamiento con agentes inmunosupresores e inmunomoduladores como la ciclosporina [9].
En nuestra institución se presentó el caso de una mujer de 56 años, con cuadro de habones pruriginosos de seis años de evolución con aparición ocasional, cuya biopsia de piel mostró edema de la dermis papilar asociado a infiltrado leucocitario de distribución perivascular. Como antecedentes personales se tenían esclerosis sistémica e hipotiroidismo con anticuerpos antitiroglobulínicos positivos. La paciente recibió tratamiento con fexofenadina en tabletas de $180 \mathrm{mg}$, dos veces al día, con adecuado control de los síntomas cutáneos. Además, recibió levotiroxina $150 \mu \mathrm{g}$ al día e hidroxicloroquina $200 \mathrm{mg}$ al día. En esta paciente se determinó un cuadro de urticaria crónica espontánea, con enfermedad autoinmune como comorbilidad.

\section{Alteraciones celulares}

Se postula que la principal alteración en algunos pacientes con urticaria crónica espontánea podría ser un mecanismo celular/ subcelular más que un mecanismo autoinmune mediado inmunológicamente $[8,13]$. A continuación, se describe la participación de algunos grupos celulares en la fisiopatología de la enfermedad.

\section{Mastocitos}

El mastocito es la principal célula implicada en la fisiopatología de la urticaria crónica espontánea; no obstante, el recuento celular en la piel con o sin lesiones urticariales no difiere entre los pacientes con urticaria crónica espontánea y los sujetos sanos $[1,8,9]$. Los mastocitos expresan en su superficie receptores activados por proteasas (PAR, por sus siglas en inglés), específicamente el PAR-1 y el PAR-2 $[8,9,18]$. La trombina, que se genera por la activación de la vía de la coagulación, puede activar al mastocito a través de los PAR-1, mientras que el complejo factor tisular/factor VIla y el complejo 
factor $\mathrm{Va} /$ factor $\mathrm{Xa}$, formados durante la activación de la cascada de la coagulación, interactúan con el PAR-2 y llevan a la degranulación de la célula [18-20]. Asimismo, la triptasa liberada por los mastocitos induce la producción de trombina mediante la activación directa de la protrombina, lo que amplifica la respuesta inflamatoria [8].

Previamente, se ha especulado un rol directo de los mastocitos en la patogénesis de la urticaria crónica espontánea debido, probablemente, a la variedad de receptores de membrana que se expresan en su superficie que pueden ser estimulados por diferentes ligandos como IgG, péptidos, derivados microbianos y fragmentos del complemento activado, que inducirían la síntesis de sustancias vasoactivas y la liberación de mediadores preformados [20]. Los mediadores de síntesis de novo, como el factor de necrosis tumoral alfa (TNF- $\alpha$ ), la interleuquina- 6 (IL-6), el factor de crecimiento del endotelio vascular (VEGF) y el factor activador de plaquetas (PAF, por sus siglas en inglés) son secretados por los mastocitos de forma independiente y son factores permeabilizadores que facilitan el desarrollo de los habones urticariales $[8,9,20]$.

A nivel intracelular puede existir una expresión anormal de las moléculas encargadas de las señales de propagación o inhibición para la activación celular de los mastocitos, luego de que el receptor para la IgE es estimulado [8]. La quinasa denominada tirosina quinasa del bazo (Syk, por sus siglas en inglés) es un regulador positivo de la señalización a través del FceRl y sus niveles son unos de los mayores determinantes para la liberación de histamina por el mastocito normal. Por el contrario, dos fosfatasas conocidas como dominio de homología $\mathrm{Src}-2$ (SH2) que contiene fosfatasas de inositol -1 y -2 (SHIP-1 y SHIP-2, por sus siglas en inglés) actúan como reguladoras negativas de la señal de propagación de los mastocitos para la acti- vación y liberación de histamina. En la urticaria crónica espontánea los niveles de SHIP-1 y SHIP-2 están disminuidos y los de Syk elevados, lo que perpetúa la activación de la célula, debido a la ausencia de los mecanismos reguladores, que lleva a un incremento en la liberación espontánea de la histamina $[1,8]$.

\section{Basófilos}

Una de las alteraciones del basófilo de particular interés es la basopenia, parcialmente explicada por la presencia de estos en la piel con y sin lesiones de los pacientes con urticaria crónica espontánea; ausentes en la piel sana $[3,8,9,13]$. Existe una correlación directa entre el grado de basopenia y la severidad de la urticaria, al igual que entre la basopenia y la presencia de autoanticuerpos [21]. También se ha demostrado una expresión incrementada del FceRI de la IgE en la superficie de los basófilos de los pacientes que sufren de urticaria crónica espontánea y una respuesta incrementada a la IL-13, que induce su activación $[9,12]$.

Dos proteínas presentes en la superficie celular, que han sido de gran interés para su uso como marcadores de la activación celular de los basófilos, son el CD63 y el CD203c. La molécula CD63 se expresa en los basófilos, y también los mastocitos, como resultado de la fusión entre los gránulos intracitoplasmáticos y la membrana plasmática, por lo que se considera un fuerte indicador de la degranulación de la célula $[8,12,13]$. Su expresión se ha encontrado incrementada en los basófilos de los pacientes con urticaria crónica espontánea y ASST positivo en comparación con los pacientes con urticaria crónica espontánea y ASST negativo, lupus eritematoso sistémico o con dermatomiositis [12,22]. No obstante, es importante resaltar que el CD63 se expresa igualmente en los monocitos y las plaquetas $[9,12,13]$. Por su parte, el CD203c es una ectoenzima que se expresa únicamente en los 
basófilos, los mastocitos y las células progenitoras hematopoyéticas $\mathrm{CD} 34^{+}$. En los basófilos su expresión se produce luego de la activación celular de forma independiente de la degranulación [8,12,13].

Igual a como sucede con los mastocitos, en la urticaria crónica espontánea hay un cambio en el paradigma de la regulación de la liberación de la histamina que es dominada por Syk debido a que, a diferencia de los basófilos normales, los niveles de SHIP-1 y SHIP-2 están disminuidos, lo que se correlaciona con el patrón de la liberación de la histamina estimulado por el anti-IgE $[1,3,8]$. De esta manera, se ha confirmado que existen diferentes fenotipos de degranulación de los basófilos en los pacientes con urticaria crónica espontánea, donde el $50 \%$ de ellos presentan reducción significativa de la liberación de la histamina basófila con estimulación con anti-lgE, relacionado con el aumento de los niveles de SHIP-2, y se conocen como no respondedores anti-lgE, y el resto de los sujetos tienen basófilos con liberación de más del $10 \%$ de su contenido de histamina luego de la estimulación con anti-lgE, al igual que niveles de SHIP-1 reducidos, y se conocen como respondedores anti-IgE $[8,13]$.

Esta alteración no parece ser debida a disfunción en la señalización intracelular del basófilo, ya que la célula responde de forma normal a los estímulos que actúan por vías independientes a la del receptor IgE, como el PAF, la bradiquinina y la proteína quimiotáctica de monocitos-1 (MCP-1, por sus siglas en inglés). Además, dado que está presente tanto en los pacientes con urticaria crónica espontánea con base autoinmune como no autoinmune, parece ser que es independiente de la presencia o niveles de autoanticuerpos. Finalmente, los niveles o expresión de las proteínas reguladoras Syk, SHIP-1 y SHIP-2 se normalizan durante la remisión de la enferme- dad, lo que reafirma que la función anormal de los basófilos puede ser un factor clave en la patogénesis de la enfermedad $[8,9]$.

\section{Eosinófilos}

A pesar de ser la célula más abundante en las biopsias de piel de pacientes con urticaria crónica espontánea se le ha dado poca atención. Se conoce que estas células se pueden activar por anticuerpos IgG contra el FcERII (CD23) de la IgE, los cuales se han encontrado presentes en cerca del $70 \%$ de los pacientes con urticaria crónica espontánea [14]. Por tal razón, se cree que tienen un rol en la patogénesis de la enfermedad, ya que la activación celular a través de este mecanismo induce la liberación de proteína básica de mielina (PBM), capaz de activar directamente el mastocito e inducir su degranulación $[9,19]$. Además, los eosinófilos pueden ser activados y reclutados por otros factores como citoquinas y quimioquinas liberadas por los mastocitos, como la inteleuquina-5 (IL-5), el TNF- $\alpha$, el PAF y la eotaxina $[9,19]$.

Los eosinófilos son también las células que expresan mayormente el factor tisular (FT), principal activador de la vía extrínseca de la coagulación, en la urticaria crónica. In vitro, el estímulo de citoquinas como el factor activador plaquetario y el factor estimulante de colonias de granulocitos y monocitos (GM-CSF, por sus siglas en inglés) incrementa su expresión. Esta célula, igualmente, es una fuente importante del factor de crecimiento de endotelio vascular (VEGF, por sus siglas en inglés) que regula la angiogénesis. Las acciones del VEGF llevan al aumento de la permeabilidad vascular y la vasodilatación, y pueden estar involucradas en la fisiopatología de la enfermedad, especialmente en los pacientes con urticaria crónica espontánea severa. Específicamente, los niveles elevados de VEGF se asocian a niveles incrementados del fragmento de pro- 
trombina $\mathrm{F} 1+2$ en plasma $\mathrm{y}$, por ende, a la activación de la cascada de la coagulación; además, se correlaciona con la severidad de la enfermedad $[19,23]$.

\section{Células dendríticas}

Las células dendríticas plasmocitoides expresan receptores tipo Toll (TLR, por sus siglas en inglés), activados por ligandos sintéticos o naturales que desencadenan una respuesta proinflamatoria, los cuales tienen un rol importante en la patogénesis de la urticaria crónica espontánea [8,24]. La secreción de interferón alfa (INF- $\alpha$ ) por las células dendríticas plasmocitoides está alterada en la urticaria crónica espontánea y se asocia a la disminución en la expresión del TLR-9, lo que indica una alteración de la célula y soporta la desregulación inmune en la urticaria crónica espontánea [8].

Se han propuesto muchas hipótesis para explicar la disminución de la expresión del TLR9 en las células dendríticas plasmocitoides, luego de ser estimuladas; es probable que la interacción entre los autoanticuerpos anti-lgE y anti-FceRI con el FceRI de las células dendríticas plasmocitoides inmaduras ocasione una función inmune alterada al suprimir la producción de INF- $\alpha$ [8]. También, es posible que la liberación de histamina en la circulación, secundaria a la degranulación de los mastocitos y los basófilos, regule diferentes tipos de células a través de la estimulación de los receptores de histamina, incluyendo las células dendríticas plasmocitoides que, al ser activadas, responden a la histamina a través de receptores $\mathrm{H} 2$, lo que produce la posterior disminución en la producción de INF- $\alpha$ [8].

La disfunción de la respuesta inmune innata en la urticaria crónica espontánea, como consecuencia de una función alterada de las células dendríticas plasmocitoides por dismi- nución del TLR-9, altera la producción de citoquinas de los linfocitos $T$, principalmente la IL-17A y la IL-10, con aumento de los niveles séricos de la IL-1, la IL-4, la IL-13, la IL-18, el TNF- $\alpha$, el factor activador de linfocitos $B$, entre otros, lo que sugiere que el proceso inflamatorio crea un ambiente adecuado para el desarrollo de la urticaria crónica espontánea [8].

\section{Vía de la coagulación y sistema del complemento}

La primera vez que se demostró la activación de la cascada de la coagulación en la urticaria crónica espontánea fue por Asero y colaboradores en 2006 [25], quienes encontraron niveles elevados de los marcadores de la coagulación como el fragmento F1+2 y describieron la activación de la vía extrínseca de la coagulación en la urticaria crónica espontánea mediante la demostración de niveles elevados del factor VII activado (FVIla) y niveles normales del factor XII activado (FXIla) en pacientes con la enfermedad. Estudios recientes señalan una posible asociación entre la coagulación y la inflamación, y el hecho de que se activan mutuamente $[26,27]$.

El factor tisular es el principal activador de la cascada extrínseca de la coagulación y está presente de forma inactiva en el citoplasma de varias células de sangre periférica como los monocitos, los eosinófilos, los neutrófilos y las plaquetas; sin embargo, como ya se mencionó, los eosinófilos son las principales células que expresan el factor tisular en la urticaria crónica espontánea [19]. La activación de los eosinófilos, durante el proceso inflamatorio, induce la liberación de mediadores incluyendo el factor tisular, con la subsecuente activación de la vía extrínseca de la cascada de la coagulación y la generación de trombina a partir de protombina por acción del factor $\mathrm{Xa}$, en presencia del factor $V$ y el calcio. Posteriormente, 
el complejo formado entre el factor tisular y el factor VIla (FT/FVIla) se une a los receptores PAR-2 en los mastocitos, lo que estimula la activación de la célula $[8,9,19]$.

Durante la conversión de la protrombina a trombina se genera el fragmento de protrombina $\mathrm{F} 1+2$, un polipéptido de $34 \mathrm{kDa}$ que es liberado en la circulación y cuyos niveles se encuentran significativamente elevados en los pacientes con urticaria crónica espontánea. La trombina es una proteasa de serina que desempeña un papel crucial en la urticaria al generar edema por medio del aumento de la permeabilidad vascular por acción directa sobre las células endoteliales, al activar e inducir la degranulación de los mastocitos a través de receptores activados por proteasa-1 (PAR-1, por sus siglas en inglés) e inducir la activación de la cascada del complemento al generar la anafilotoxina $\mathrm{C} 5$ a en ausencia de $\mathrm{C} 3[8,12,19]$.

La liberación de la histamina por los mastocitos, inducida por autoanticuerpos anti $\alpha$-FcERI, se incrementa con la activación del C5a. El mecanismo por el cual esto sucede es explicado por la unión de forma adyacente de dos moléculas de IgG anti-FcERI a dos cadenas alfa en los mastocitos y basófilos, lo que activa el C5a, el cual, a su vez, activa el mastocito $[3,19]$. Cabe resaltar que la liberación de histamina inducida por la generación del C5a es principalmente a nivel cutáneo, debido a que los receptores para esta molécula ( $\mathrm{C} 5 \mathrm{aR}$ ) solo se expresan en los mastocitos de la piel; una hipótesis que podría explicar por qué los pacientes con urticaria crónica espontánea no experimentan síntomas respiratorios [13,18].

La activación de la cascada de la coagulación lleva como paso final a la formación de fibrina y la posterior fibrinólisis; no obstante, aún no es claro si la activación de esta vía tiene un papel principal en la patogénesis de la urticaria cróni- ca espontánea o si simplemente actúa como un sistema de amplificación [13,18,19]. El dímero $D$, un producto de la degradación de la fibrina de 180 kD, liberado en la sangre luego de la lisis del trombo (fibrinólisis), se correlaciona con la severidad de la enfermedad y podría predecir la falta de respuesta a los antihistamínicos. Sin embargo, la elevación de sus niveles no es específica de la urticaria crónica espontánea, ya que también se encuentra aumentado en otras patologías como el angioedema hereditario y el pénfigo bulloso $[13,18,19]$.

Diversa evidencia sugiere que los sistemas de coagulación, fibrinólisis y complemento desempeñan un papel importante en la patogénesis de la urticaria crónica espontánea, por lo que la evaluación de sus marcadores podría ser de ayuda en el manejo de la enfermedad [19]. A pesar de su relativa inespecificidad, la medición de los niveles de dímero $D$ puede proponerse para evaluar la severidad de la enfermedad $y$, posiblemente, predecir la respuesta al tratamiento con antihistamínicos [19]. Es interesante anotar que durante los periodos de remisión de la enfermedad los niveles de este biomarcador regresan a la normalidad [19].

Por su parte, la hipercoagulación que ocurre en la urticaria crónica espontánea está poco asociada con un incremento en el riesgo de trombosis; esto debido a una eficiente activación del sistema de fibrinólisis y la localización extravascular de los depósitos de fibrina [28]. Se ha evidenciado que el tratamiento con anticoagulantes $y$, más recientemente, con heparina, en pacientes con altos niveles de dímero $D$ y pobre respuesta a los antihistamínicos, es eficaz para la disminución de los síntomas; sin embargo, aún faltan estudios que confirmen estos hallazgos [8].

En la figura 3 se esquematiza la vía de la coagulación y del sistema de complemento 


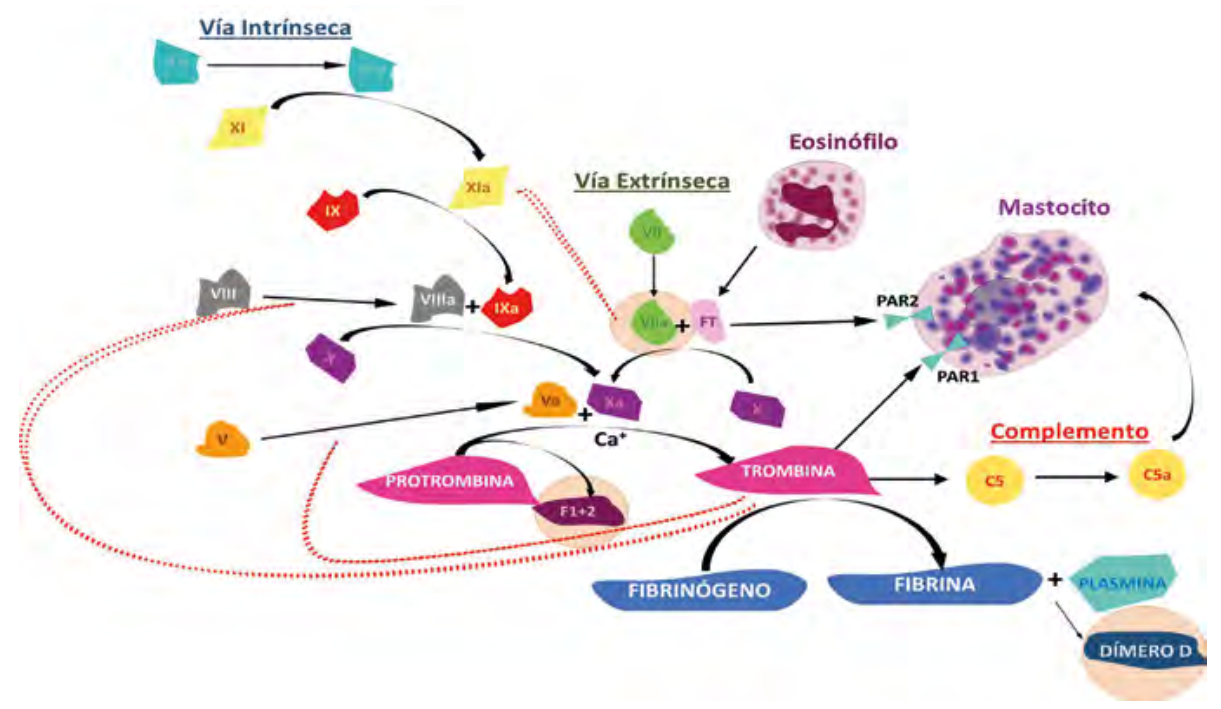

Figura 3. Vía de la coagulación y sistema de complemento. La activación del mastocito puede ocurrir a través de diferentes mecanismos que pueden ser independientes o pueden coexistir en un mismo paciente. El complejo FT/FVIIa activa al mastocito a través del receptor PAR-2, mientras que la trombina lo hace a través del receptor PAR-1. Además, la trombina induce la activación de la anafilotoxina C5a, en ausencia de C3, lo que amplifica la respuesta inflamatoria inducida por los autoanticuerpos anti $\alpha-F c \varepsilon R I$ de la lgE.

que llevan a la activación de los mastocitos y la liberación del dímero $D$ en pacientes con urticaria crónica espontánea.

\section{Asociación con infecciones}

\section{Parásitos}

El vínculo entre la urticaria crónica espontánea y la infección por parásitos se ha descrito en la literatura desde hace varios años [29]. Se han realizado múltiples esfuerzos para aclarar la prevalencia, los mecanismos inmunológicos y el comportamiento de la urticaria crónica espontánea secundaria a infecciones parasitarias; no obstante, la amplia distribución mundial de los parásitos ha dificultado tener información reproducible y aplicable en la práctica clínica
[30]. Esto, debido principalmente a que los hallazgos varían según la especie de parásito involucrado y los mecanismos inmunes del hospedador en respuesta a este [31]. Los parásitos son más frecuentes en las regiones intertropicales; sin embargo, son altamente prevalentes en todo el mundo, incluso, se describe que más del $24 \%$ de la población mundial presenta parasitosis intestinales [32].

Actualmente, se han descrito en el mundo tres escenarios diferentes de acuerdo con la influencia de las parasitosis en la respuesta inmunológica [33]:

1. Países endémicos: corresponde a aquellos en los que la inmunosupresión causada por los parásitos tiene un impacto negativo sobre las enfermedades emergentes y la eficacia de la vacunación. 
2. Países desarrollados: corresponde a aquellos en los que la erradicación de las parasitosis parece estar relacionada con el aumento de las enfermedades inflamatorias crónicas.

3. Países en etapa de transición económica: corresponde a aquellos en donde hay menor prevalencia de las parasitosis, acceso parcial a campañas de desparasitación y persistencia de las condiciones de sanidad precarias en una parte importante de la población, lo que permite que se perpetúe el ciclo de vida del parásito y ocurran reinfecciones.

Los helmintos, específicamente, inducen en el hospedero una forma de respuesta inmune tipo 2 parecida a la alérgica [34]. De esta manera, el estudio de la inducción de una respuesta antinflamatoria por los parásitos, mediante diferentes mecanismos para preservar su permanencia en el hospedero, ha sido de gran interés, ya que puede ser de utilidad en el tratamiento de las enfermedades inflamatorias crónicas [33].

Aunque no se puede generalizar sobre los efectos de los parásitos intestinales en la respuesta inmunológica, se han identificado algunos posibles mecanismos responsables de la activación y la subsecuente degranulación del mastocito, que son independientes de la IgE [33] (véase tabla 1). No obstante, la respuesta reguladora que ellos también generan desempeña un papel crucial en la amplia variedad y presentación de la urticaria, que va desde pacientes asintomáticos hasta pacientes en los que la erradicación de la infección conduce a mejoramiento de los síntomas de la enfermedad, un control adecuado de la misma con dosis menores de antihistamínicos e incluso una remisión completa [35].
La vinculación de los parásitos como causa de la urticaria crónica espontánea es poco frecuente. Se describe que se presenta en menos del $5 \%$ en niños, lo que hace que tenga una mayor relevancia al ser una población vulnerable a la infección por parásitos, debido a que aún no han adoptado las medidas de higiene necesarias como lo hacen los adultos. En los niños con urticaria crónica espontánea la resolución de la enfermedad se presenta luego de la erradicación parasitaria, principalmente en aquellos que presentaban síntomas gastrointestinales asociados a la infestación [7].

De esta manera, la recomendación es realizar una adecuada anamnesis y estudiar las parasitosis en aquellos casos de urticaria crónica espontánea en los que se encuentran síntomas gastrointestinales, pero aclarándole al paciente las expectativas que debe tener con el tratamiento, debido a que la erradicación del parásito no es garantía de la resolución de los síntomas, pues existen diferentes mecanismos inmunológicos que se pueden desencadenar ante una parasitosis. Por lo tanto, se requieren más estudios para lograr esclarecer el comportamiento de las diferentes parasitosis y sus repercusiones en la urticaria crónica espontánea.

Con base en lo anterior, es claro que los parásitos pertenecen al grupo de las infecciones asociadas a la urticaria crónica espontánea. No obstante, solo en el subgrupo de pacientes en los que se identifican a los parásitos como el factor desencadenante de los síntomas, y en los que la erradicación de la infección logra una resolución completa del cuadro urticarial, se podría pensar que se trata realmente de una urticaria crónica espontánea, pues, si se considera que los parásitos son agentes 


\begin{tabular}{ll}
\hline Tabla 1. Mecanismos fisiopatológicos de los parásitos [33,36,37] \\
\hline Efecto directo del parásito & $\begin{array}{l}\text { Mecanismo de activación y degranulación de los } \\
\text { mastocitos }\end{array}$ \\
\hline $\begin{array}{l}\text { Liberación de alarminas por lesión tisular tras el } \\
\text { ingreso del parásito }\end{array}$ & $\begin{array}{l}\text { Activación y degranulación de los mastocitos } \\
\text { Activación de células linfoides innatas que participan en } \\
\text { los mecanismos de resistencia frente al parásito }\end{array}$ \\
$\begin{array}{l}\text { Liberación de productos que inhiben las células } \\
\text { dendríticas }\end{array}$ & $\begin{array}{l}\text { Favorece la diferenciación de células T vírgenes en célu- } \\
\text { las Th2 en los ganglios linfáticos }\end{array}$ \\
$\begin{array}{l}\text { Formación de complejos inmunes con IgG1 e IgG3 } \\
\text { fijadoras de complemento }\end{array}$ & $\begin{array}{l}\text { Activación del sistema del complemento, generación de } \\
\text { anafilatoxinas C5a y C3a activadoras de los mastocitos }\end{array}$ \\
$\begin{array}{l}\text { Activación de eosinófilos } \\
\text { Activación de eosinófilos }\end{array}$ & $\begin{array}{l}\text { Liberación de TNF activador de la cascada de coagulación } \\
\text { que conduce a la formación de trombina responsable de } \\
\text { la activación y degranulación de los mastocitos }\end{array}$ \\
\hline
\end{tabular}

externos, que al infectar al hospedero inducen una respuesta inmune $y$, por ende, el desarrollo de signos y síntomas, se podría establecer como una urticaria crónica inducible. Por tal razón, es posible que la clasificación actual para las urticarias pueda sufrir cambios en el futuro, donde se trate de aclarar si el paciente tiene o no un factor claro desencadenante de los síntomas de la urticaria (véase figura 4).

\section{Helicobacter pylori}

En nuestra institución también se presentó el caso de un hombre de 29 años que presentaba desde cuatro años atrás habones pruriginosos para los cuales recibía omalizumab, a una dosis de $300 \mathrm{mg}$ por vía subcutánea, cada mes desde tres años atrás. El paciente describió que, además, tuvo consultas por el servicio de urgencias debido a dolor abdominal en marco cólico, con distención abdominal, sin emesis ni cambios en las deposiciones, para lo cual recibió antiparasitarios sin éxito. Ante la persistencia del dolor se le realizó estudio por endoscopia del tracto digestivo superior, el cual reportó la presencia de Helicobacter pylori, para el que recibió tratamiento de erradicación con un resultado exitoso. En el último año presentaba adecuado control de los síntomas cutáneos, con remisión de la urticaria crónica espontánea, aun cuando suspendió el tratamiento para el control de los síntomas. De esta manera, se confirma que se trata de un paciente con cuadro de urticaria crónica espontánea e infección por Helicobacter pylori como comorbilidad.

Helicobacter pylori, previamente conocido como Campylobacter pylori, es un bacilo móvil, curvado y Gram negativo, que se localiza en el epitelio mucoso gástrico y, en ocasiones, en el epitelio mucoso duodenal o esofágico. Esta bacteria fue aislada por primera vez en el ser humano en 1982. Su importancia en la práctica clínica radica en su amplia distribución a nivel mundial y alta prevalencia, que la cataloga como la infección bacteriana crónica más común en el mundo. La prevalencia de la infección por Helicobacter pylori es variable, y depende de la edad del paciente y la geografía donde se presente. Se ha indicado que la infección aumenta con la edad; el $10 \%$ de los infectados tienen entre 18 y 30 


\section{Urticaria crónica}

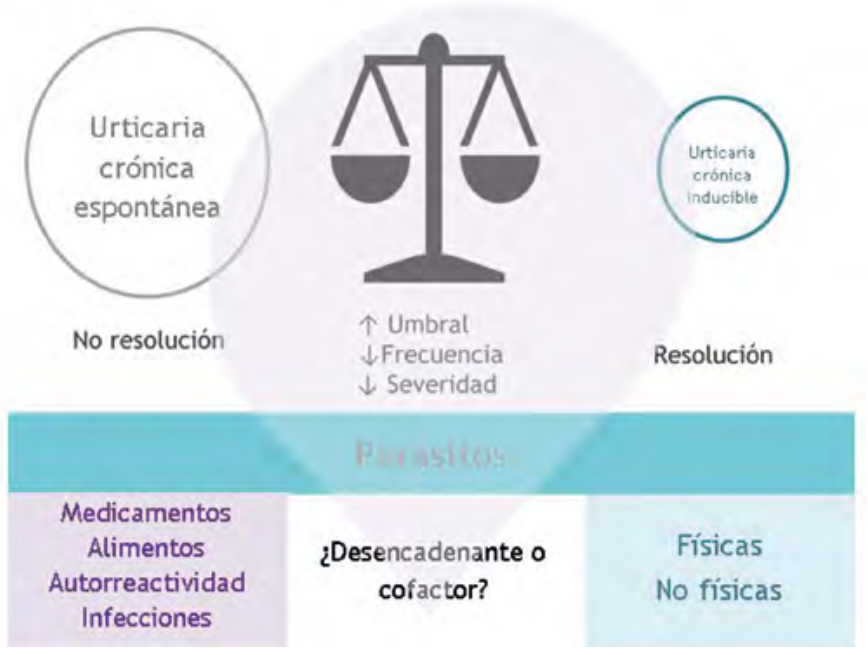

Figura 4. Brechas en la clasificación de urticaria crónica. Las infecciones por parásitos pertenecen al grupo de la urticaria crónica espontánea; no obstante, en el subgrupo de pacientes en los que se identifican a los parásitos como el factor desencadenante de los síntomas y en los que la erradicación de la infección logra una resolución completa del cuadro urticarial se podría pensar que se trata realmente de una urticaria inducible. La respuesta inmune en el hospedero frente a los parásitos, que son agentes externos, sería reproducible ante la reinfección, con la consiguiente reproducción de los síntomas.

años de edad mientras que el $50 \%$ tienen más de 60 años [38]. La mayoría de las personas colonizadas por Helicobacter pylori se encuentran asintomáticas, pero la presencia de la bacteria se asocia con un riesgo aumentado de ulcera péptica y cáncer gástrico. Algunos pacientes pueden presentar dolor abdominal, náuseas, dispepsia, emesis, pérdida de peso y del apetito [39].

Actualmente, el diagnóstico y tratamiento para la infección por Helicobacter pylori, como una estrategia de manejo comprobada, se recomienda para los pacientes con dispepsia no investigada, ulcera péptica, linfoma MALT, anemia ferropénica de causa no clara, antecedente familiar en primer grado de cáncer gástrico y antecedente de cáncer gástrico que recibió tratamiento quirúrgico [40].
El papel de la infección por Helicobacter pylori en la urticaria crónica espontánea se ha investigado, pero sus resultados han sido polémicos. Varios autores han demostrado que la erradicación de la bacteria se asocia con una remisión de los síntomas urticariales, lo que sugiere su posible participación en la patogénesis de la urticaria crónica espontánea $[6,41]$. Entre los mecanismos que podría explicar este vínculo se ha descrito que la activación y la degranulación de los mastocitos se puede llevar a cabo por mecanismos independientes de IgE, más vinculados con la inmunidad innata, durante la infección por Helicobacter pylori $[42,43]$.

Se ha informado que algunos componentes proteínicos de la bacteria no solo participan en la reacción de fase temprana de la urticaria crónica espontánea, mediante la 


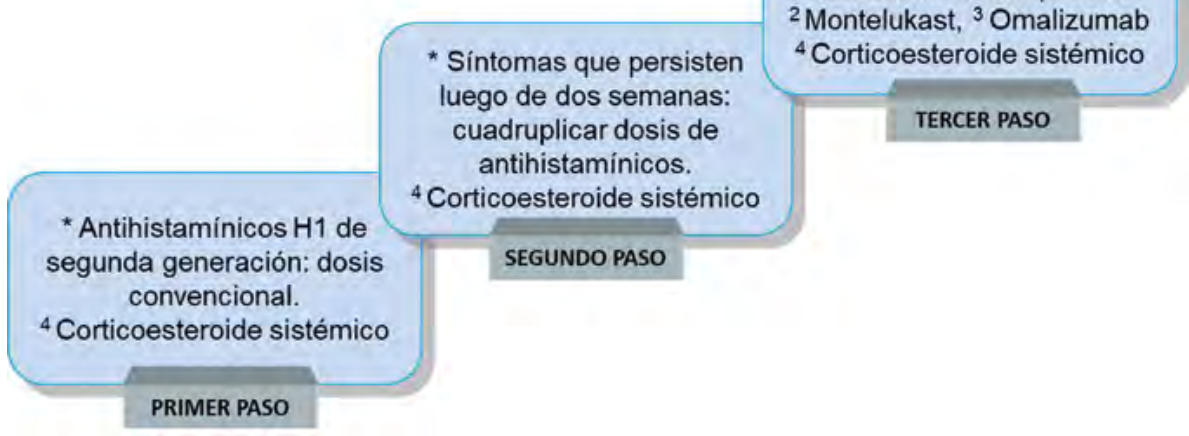

Sintomas que persisten por más de una a cuatro semanas: ${ }^{1}$ Ciclosporina,

${ }^{2}$ Montelukast, ${ }^{3}$ Omalizumab

${ }^{4}$ Corticoesteroide sistémico

TERCER PASO

Figura 5. Escalonamiento en el manejo del paciente con urticaria crónica espontánea. *Fuerte recomendación, alta calidad de la evidencia, bajos costos y amplia disponibilidad, buen perfil de seguridad y eficacia. ^Adicional al antihistamínico; puede ser cualquiera de los siguientes: ${ }^{1}$ Ciclosporina: fuerte recomendación, alta calidad de la evidencia, mediano a alto costo, moderado perfil de seguridad y buena eficacia, ${ }^{2}$ Montelukast: recomendación débil, baja calidad de la evidencia, bajo costo, buen perfil de seguridad y eficacia, ${ }^{3}$ Omalizumab: fuerte recomendación, alta calidad de la evidencia, alto costo, buen perfil de seguridad y eficacia, ${ }^{4}$ Corticoesteroides sistémicos: uso máximo durante 10 días, solo en casos de exacerbación aguda, recomendación débil, baja calidad de la evidencia, bajo costo, buen perfil de seguridad solo en cursos cortos.

estimulación de la liberación de la histamina en los mastocitos, sino que también participan en la fase final de la reacción mediante la estimulación de los mastocitos para sintetizar y secretar continuamente más mediadores inflamatorios como el TNF- $\alpha$, la IL-3, el interferón gamma (IFN- $\gamma$ ) y el leucotrieno B4 (LTB4) [44].

Además, los anticuerpos IgG e IgA frente a lipoproteínas conservadas de Helicobacter pylori, que pueden actuar como una fuente de autoinmunidad, podrían desempeñar un papel en la patogénesis de un subtipo de urticaria crónica en la que se presenta reactividad cruzada entre las lipoproteínas bacterianas y algunos componentes de la piel [45].

No obstante, es importante aclarar que la remisión o la mejoría de los síntomas urticariales, después de la erradicación de Helicobacter pylori, no se generaliza en todos los pacientes, como se ha encontrado en varios estudios $[6,46]$.

\section{Tratamiento}

Las guías de la Academia Europea de Alergia e Inmunología Clínica, la Red Europea de Alergia y Asma Global, el Foro Europeo de Dermatología y la Organización Mundial de Alergia (EAACl/GA²LEN/EDF/WAO, por sus siglas en inglés) recomiendan un tratamiento escalonado para el manejo de la urticaria crónica espontánea, siendo los antihistamínicos $\mathrm{H} 1$ de segunda generación el tratamiento de primera línea y el aumento de la dosis de estos medicamentos, el tratamiento de segunda línea [2,47-52]. En la figura 5 se propone un escalonamiento en el manejo del paciente con urticaria crónica espontánea. 


\section{Antihistamínicos}

Los antihistamínicos son fármacos que actúan como agonistas inversos que interactúan con los receptores $\mathrm{H} 1$, lo que favorece su conformación inactiva [4749]. Los antihistamínicos $\mathrm{H} 1$ de segunda generación son mínimamente o no sedantes, debido a su baja penetración de la barrera hematoencefálica, son altamente selectivos $y$ tienen un mejor perfil de efectos adversos, incluso a altas dosis, en comparación con los de primera generación, por lo cual se consideran como el tratamiento de primera línea. Desafortunadamente, se estima que los antihistamínicos mejoran los síntomas de forma efectiva en menos del $50 \%$ de los pacientes con urticaria crónica espontánea [47-49].

Las guías indican que en los pacientes refractarios a las dosis estándares de los antihistamínicos $\mathrm{H} 1$ el segundo paso es duplicar y hasta cuadruplicar la dosis inicial. La evidencia sugiere que las altas dosis de antihistamínicos $\mathrm{H} 1$ aumentan el rango de pacientes respondedores, sin cambios relevantes en el perfil de seguridad [48-50]. Los pacientes que permanecen refractarios a las altas dosis de antihistamínicos $\mathrm{H} 1$ requieren tratamientos alternativos. En el tratamiento de tercera línea se incluyen los tres agentes descritos a continuación.

\section{Omalizumab}

El omalizumab es un anticuerpo monoclonal recombinante humano de la clase IgG1, aprobado para el tratamiento de la urticaria crónica espontánea en pacientes mayores de 12 años que permanecen sintomáticos a pesar del tratamiento con antihistamínicos $\mathrm{H} 1$ [2,51,52]. Los estudios han mostrado un rango de respuesta mayor al $80 \%$ con el uso de omalizumab [47-49].
El omalizumab se une de forma selectiva al dominio C3 de la cadena pesada de la IgE $y$, de esta forma, reduce los niveles séricos libres de la IgE y disminuye la expresión del receptor de alta afinidad de la misma en la superficie celular de los mastocitos y los basófilos [47-49]. La calidad de la evidencia documenta la eficacia del omalizumab en la urticaria crónica espontánea con buenos perfiles de seguridad y eficacia, desafortunadamente su costo es muy alto $[2,51,52]$.

\section{Ciclosporina}

La ciclosporina es un fármaco que posee una actividad inmunomoduladora y un efecto antinflamatorio intrínseco mediante la inhibición directa de la liberación de histamina y otros mediadores preformados en los mastocitos y basófilos [48-50]. Es una alternativa útil en los pacientes con urticaria crónica espontánea mediada por un desorden autoinmune [49-51].

\section{Inhibidor de los leucotrienos}

Los leucotrienos son mediadores proinflamatorios potentes cuyos efectos son bloqueados con el uso de antagonistas de su receptor [48-50]. Los inhibidores de leucotrienos tienen como ventajas su menor precio y un perfil de seguridad favorable. Cuando se utilizan en combinación con los antihistamínicos $\mathrm{H} 1$ parece que tienen una mayor efectividad respecto al uso de solo los antihistamínicos; sin embargo, algunos estudios no han demostrado estos resultados [49-51].

El uso de los inhibidores de leucotrienos se considera especialmente cuando el omalizumab no está disponible, está contraindicado o no fue bien tolerado. La combinación de antihistamínicos y 
antileucotrienos podría ser más efectiva en los pacientes con urticaria crónica espontánea exacerbada por antinflamatorios no esteroideos (AINES) [2,51,52].

\section{Conclusiones}

Es probable que los diferentes mecanismos patogénicos de la urticaria, como la autorreactividad, los defectos celulares, la activación del sistema de la coagulación y el sistema del complemento ya mencionados, actúen de forma sinérgica o secuencial, bien sea como mecanismos entrecruzados o independientes, para activar los mastocitos e inducir en ellos la liberación de los mediadores preformados o la secreción de nuevos mediadores vasoactivos para producir la expresión clínica final de la enfermedad.

Dado el hallazgo de pacientes que presentan urticaria crónica espontánea con componente inducible, es necesario adecuar una clasificación donde se incluya este fenotipo, el cual se asocia a una mayor duración de la enfermedad y severidad de los síntomas [5].

La literatura apoya el tratamiento de las parasitosis en pacientes con urticaria crónica espontánea cuando presentan síntomas activos de la infección [8], pero, de acuerdo con la experiencia de los autores, no es recomendable realizar la desparasitación de forma rutinaria de los pacientes con urticaria crónica.

Las señales para la resolución de la urticaria aún no están bien caracterizadas, involucran la disminución de la expresión del receptor de histamina, la reconstitución de la integridad del endotelio, la apoptosis de células inflamatorias, el aclaramiento del detrito celular por los macrófagos y el drenaje del edema en la circulación [8].

\section{Agradecimientos}

A Manuela Tejada Giraldo, Ingeniera Biológica, y a Víctor Calvo Betancur, Epidemiólogo Computacional, por su apoyo en la revisión de este manuscrito.

\section{Bibliografía}

1. Altman $\mathbf{K}$, Chang C. Pathogenic intracellular and autoimmune mechanisms in urticaria and angioedema. Clin Rev Allergy Immunol 2013; 45: 4762.

2. Moolani Y, Lynde C, Sussman G. Advances in Understanding and Managing Chronic Urticaria. F1000Res. Vol. 5 (ed 2016/03/08); 2016: 177.

3. Saini SS. Chronic spontaneous urticaria: etiology and pathogenesis. Immunol Allergy Clin North Am 2014; 34: 33-52.

4. Magerl M, Altrichter S, Borzova E, Gimenez-Arnau A, Grattan CE, Lawlor F, et al. The definition, diagnostic testing, and management of chronic inducible urticarias - The EAACI/GA(2) LEN/EDF/ UNEV consensus recommendations 2016 update and revision. Allergy 2016; 71: 780-802.

5. Sánchez J, Amaya E, Acevedo A, Celis A, CarabaIlo D, Cardona R. Prevalence of Inducible Urticaria in Patients with Chronic Spontaneous Urticaria: Associated Risk Factors. J Aller Cl Imm-Pract 2017; 5: 464-470.

6. Gu H, Li L, Gu M, Zhang G. Association between Helicobacter pylori Infection and Chronic Urticaria: A Meta-Analysis. Gastroenterol Res Pract 2015; 2015: 486974

7. Arik Yilmaz E, Karaatmaca B, Sackesen C, Sahiner UM, Cavkaytar O, Sekerel BE, et al. Parasitic Infections in Children with Chronic Spontaneous Urticaria. Int Arch Allergy Imm 2016; 171: 130135.

8. Jain S. Pathogenesis of Chronic Urticaria: An Overview. Dermatol Res Pract 2014; 2014: 10.

9. Ferrer M. Immunological events in chronic spontaneous urticaria. Clin Transl Allergy 2015; 5: 30.

10. Criado PR, Criado RFJ, Maruta CW, dos Reis VMS. Chronic urticaria in adults: state-of-the-art in the new millennium. An Bras Dermatol 2015; 90: 74-89

11. Sabroe RA, Fiebiger E, Francis DM, Maurer D, Seed PT, Grattan CE, et al. Classification of antiFcepsilonRI and anti-IgE autoantibodies in chronic idiopathic urticaria and correlation with di- 
sease severity. J Allergy Clin Immunol 2002; 110 : 492-499.

12. Boguniewicz $\mathbf{M}$. The autoimmune nature of chronic urticaria. Allergy Asthma Proc 2008; 29: 433-438.

13. Konstantinou GN, Asero R, Ferrer M, Knol EF, Maurer M, Raap U, et al. EAACl taskforce position paper: evidence for autoimmune urticaria and proposal for defining diagnostic criteria. J Allergy Clin Immunol 2013; 68: 27-36.

14. Puccetti A, Bason C, Simeoni S, Millo E, Tinazzi E, Beri R, et al. In chronic idiopathic urticaria autoantibodies against Fc epsilonRII/CD23 induce histamine release via eosinophil activation. Clin Exp Allergy 2005; 35: 1599-1607.

15. Fine LM, Bernstein JA. Guideline of Chronic Urticaria Beyond. Allergy Asthma Immun 2016; 8: 396-403.

16. O'Donnell BF, O'Neill CM, Francis DM, Niimi N, Barr RM, Barlow RJ, et al. Human leucocyte antigen class II associations in chronic idiopathic urticaria. Br J Dermatol 1999; 140: 853-858.

17. Calamita Z, Bronhara Pela Calamita A. HLA in patients with chronic spontaneous urticaria who are positive for anti-thyroid antibodies. J Eur Acad Dermatol Venereol 2013; 27: 661-662.

18. Vena GA, Cassano N, Marzano AV, Asero R. The Role of Platelets in Chronic Urticaria. Int Arch Allergy Inmunol 2016; 169: 71-79.

19. Tedeschi A, Kolkhir P, Asero R, Pogorelov D, Olisova $\mathrm{O}$, Kochergin N, et al. Chronic urticaria and coagulation: pathophysiological and clinical aspects. Allergy 2014; 69: 683-691.

20. Bossi F, Frossi B, Radillo O, Cugno M, Tedeschi A, Riboldi $P$, et al. Mast cells are critically involved in serum-mediated vascular leakage in chronic urticaria beyond high-affinity IgE receptor stimulation. Allergy 2011; 66: 1538-1545.

21. Eckman JA, Hamilton RG, Gober LM, Sterba PM, Saini SS. Basophil phenotypes in chronic idiopathic urticaria in relation to disease activity and autoantibodies. J Invest Dermatol 2008; 128: 1956-1963.

22. Gyimesi E, Sipka S, Danko K, Kiss E, Hidvegi B, Gal M, et al. Basophil CD63 expression assay on highly sensitized atopic donor leucocytes-a useful method in chronic autoimmune urticaria. $\mathrm{Br} \mathrm{J}$ Dermatol 2004; 151: 388-396.

23. Tedeschi A, Asero R, Marzano AV, Lorini M, Fanoni D, Berti E, et al. Plasma levels and skineosinophil-expression of vascular endothelial growth factor in patients with chronic urticaria. Allergy 2009; 64: 1616-1622.
24. Hartmann G, Battiany J, Poeck H, Wagner M, Kerkmann M, Lubenow N, et al. Rational design of new $\mathrm{CpG}$ oligonucleotides that combine B cell activation with high IFN-alpha induction in plasmacytoid dendritic cells. Eur J Immunol 2003; 33: 1633-1641.

25. Asero R, Tedeschi A, Riboldi P, Cugno M. Plasma of patients with chronic urticaria shows signs of thrombin generation, and its intradermal injection causes wheal-and-flare reactions much more frequently than autologous serum. J Allergy Clin Immunol 2006; 117: 1113-1117.

26. Cugno M, Tedeschi A, Asero R, Meroni PL, Marzano AV. Skin autoimmunity and blood coagulation. Autoimmunity 2010; 43: 189-194.

27. Marzano AV, Tedeschi A, Berti E, Fanoni D, Crosti C, Cugno M. Activation of coagulation in bullous pemphigoid and other eosinophil-related inflammatory skin diseases. Clin Exp Immunol 2011; 165: 44-50.

28. Cugno M, Asero R, Tedeschi A, Lazzari R, Marzano AV. Inflammation and coagulation in urticaria and angioedema. Curr Vasc Pharmacol 2012; 10: 653-658.

29. Harris RH, Mitchell JH. Chronic urticaria due to giardia lamblia. Arch dermatology Syphilol 1949; 59: 587-589.

30. Casero RD, Mongi F, Sanchez A, Ramirez JD. Blastocystis and urticaria: Examination of subtypes and morphotypes in an unusual clinical manifestation. Acta Trop 2015; 148: 156-161.

31. Osada Y, Kanazawa T. Parasitic helminths: new weapons against immunological disorders. J Biomed Biotechnol 2010; 2010: 743758.

32. Kolkhir P, Balakirski G, Merk HF, Olisova $O$, Maurer M. Chronic spontaneous urticaria and internal parasites--a systematic review. Allergy 2016; 71: 308-322.

33. Zakzuk J. Inmunorregulación inducida por helmintos: una actualización. latreia 2016; 29: 182 193.

34. Dilek AR, Dilek N, Saral Y, Ekşi S. The role of protozoa in the etiology of chronic urticaria. Dermatol Sin 2012; 30: 90-92.

35. Daschner A, Vega de la Osada F, Pascual CY. Allergy and parasites reevaluated: wide-scale induction of chronic urticaria by the ubiquitous fish-nematode Anisakis simplex in an endemic region. Allergol Immunopathol (Madr) 2005; 33: 31-37.

36. Lepczynska M, Chen WC, Dzika E. Mysterious chronic urticaria caused by Blastocystis spp.? Int J Dermatol 2016; 55: 259-266; quiz 263-254, 266. 
37. Minciullo PL, Cascio A, Isola S, Gangemi S. Different clinical allergological features of Taenia solium infestation. Clin Mol Allergy 2016; 14: 18.

38. Cover TL, Blaser MJ. Helicobacter pylori y otras especies gástricas de Helicobacter. En: Bennett JE, Dolin R, Blaser MJ, eds. Mandell, Douglas y Bennett-Enfermedades infecciosas: Principios y práctica. Vol. 2. España: Elsevier; 2016: 26312639.

39. Gurney S, Carvalho L, Gonzalez C, Galaviz E, Sonstein F. An Efficacious and Cost-Effective Pharmacologic Treatment for Helicobacter pylori. J Nurse Pract 2014; 10: 22-29.

40. Otero W, Trespalacios AA, Otero L, Vallejo MT, Torres Amaya M, Pardo R, et al. Guía de práctica clínica para el diagnóstico y tratamiento de la infección por Helicobacter pylori en adultos. Rev Col Gastroenterol 2015; 30: 17-33.

41. Shiotani A, Okada K, Yanaoka K, Itoh H, Nishioka S, Sakurane $M$, et al. Beneficial effect of Helicobacter pylori eradication in dermatologic diseases. Helicobacter 2001; 6: 60-65.

42. Supajatura V, Ushio H, Wada A, Yahiro K, Okumura $\mathbf{K}$, Ogawa $\mathbf{H}$, et al. Cutting edge: VacA, a vacuolating cytotoxin of Helicobacter pylori, directly activates mast cells for migration and production of proinflammatory cytokines. J Immunol 2002; 168: 2603-2607.

43. Tsai CC, Kuo TY, Hong ZW, Yeh YC, Shih KS, Du SY, et al. Helicobacter pylori neutrophil-activating protein induces release of histamine and interleukin- 6 through $\mathrm{G}$ protein-mediated MAPKs and PI3K/Akt pathways in HMC-1 cells. Virulence 2015; 6: 755-765.

44. Tan R-J, Sun H-Q, Zhang W, Yuan H-M, Li B, Yan H-T, et al. A 21-35 kDa Mixed Protein Component from Helicobacter pylori Activates Mast Cells Effectively in Chronic Spontaneous Urticaria. Helicobacter 2016; 21: 565-574.
45. Bakos N, Fekete B, Prohaszka Z, Fust G, Kalabay L. High prevalence of $\operatorname{IgG}$ and IgA antibodies to 19-kDa Helicobacter pylori-associated lipoprotein in chronic urticaria. Allergy 2003; 58: 663667.

46. Liutu M, Kalimo K, Uksila J, Savolainen J. Extraction of IgE-binding components of Helicobacter pylori by immunoblotting analysis in chronic urticaria patients. Int Arch Allergy Immunol 2001; 126: 213-217.

47. Vestergaard C, Toubi E, Maurer M, Triggiani $M$, Ballmer-Weber B, Marsland A, et al. Treatment of chronic spontaneous urticaria with an inadequate response to $\mathrm{H} 1$-antihistamines: an expert opinion. Eur J Dermatol 2017; 27: 10-19.

48. Greiwe J, Bernstein JA. Therapy of antihistamine-resistant chronic spontaneous urticaria. Expert Review of Clinical Immunology 2017; 13: 311-318.

49. Zuberbier $T$, Aberer $W$, Asero R, Bindslev-Jensen C, Brzoza Z, Canonica GW, et al. Methods report on the development of the 2013 revision and update of the EAACI/GA2 LEN/EDF/WAO guideline for the definition, classification, diagnosis, and management of urticaria. Allergy 2014; 69: e129.

50. Kulthanan $K$, Tuchinda $P$, Chularojanamontri $L$, Chanyachailert P, Korkij W, Chunharas A, et al. Clinical practice guideline for diagnosis and management of urticaria. Asian Pac J Allergy 2016; 34: 190-200.

51. Powell RJ, Leech SC, Till S, Huber PA, Nasser SM, Clark AT. BSACI guideline for the management of chronic urticaria and angioedema. Clin Exp Allergy 2015; 45: 547-565.

52. Vestergaard C, Deleuran M. Chronic spontaneous urticaria: latest developments in aetiology, diagnosis and therapy. Ther Adv Chronic Dis 2015; 6: 304-313.

\begin{abstract}
Chronic spontaneous urticaria is a disease that produces a great compromise in patient's quality of life. The associated pathophysiological mechanisms are still largely unknown because they are not generalizable to all individuals. There are intrinsic and extrinsic factors involved in the development and persistence of the disease that can act individually or coexist. In this review are proposing some changes in the current classification of the disease, which includes a subdivision into the chronic urticaria called mixed chronic urticaria that makes reference to cases where intrinsic and extrinsic factors coexist for the onset of the disease in the same individual. Some viral, bacterial and parasite infectious processes have been associated with the development or severity of chronic urticaria symptoms in a subgroup of patients, therefore, they are included as extrinsic factors to the individual within chronic inducible urticaria non-physical. These modifications are proposed in order to optimized the diagnosis and treatment of patients with chronic spontaneous urticaria.
\end{abstract}

Key words: Urticaria, spontaneous chronic urticaria, mixed chronic urticaria, parasitic infections, Helicobacter pylori. 
$\pi$ Laboratorio ${ }^{\top}$

Clínico

U Hematológico

\section{Creemos en los sueños de todos los colombianos que llevan en la sangre confianza}

咅

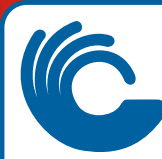

ISO 9001

\$ icontec

Sede Principal Poblado: Carrera 43C No. 5-33

Toma de Muestras: Centro Comercial Sandiego, Torre Norte, Piso 10, No. 1034

Teléfono: 4444200 - www.Ich.co - Medellín 